\title{
Kültürel Zekanın Girişimcilik Yönelimine Etkisi: Laleli Pazarındaki Mikro Ölçekli İşletmelerde Bir Araştırma
}

\author{
Ümmügülsüm KOYUNCU* $\quad$ Buket AKDÖL ${ }^{* *}$
}

\begin{abstract}
$\ddot{O} Z$
Rekabetin hızla arttığ günümüz iş dünyasında, işletmelerin uluslararası düzeyde faaliyet gösterme zorunluluğu artmaktadır. Söz konusu faaliyetler esnasında, uluslararası alanda farklı kültürel özelliklere sahip bireylerin etkileşimi ile iletişim sorunları ortaya çıkabilmektedir. Bu sorunun aşılmasında kültürel zeka etkili bir faktör olarak son dönemde yönetim bilimcilerin ilgisini çekmektedir. Bu çalışmanın amacı, kültürel zekanın girişimcilik yönelimine etkisini belirlemektir. Bu amaçla Laleli pazarındaki mikro ölçekli işletmelerden anket yöntemi ile veri toplanmıştır. Anket formunda kültürel zeka ölçeği (Ang, Van Dyne, Koh, Ng, Templer, Tay ve Chandrasekar 2007) ile girişimcilik yönelimi ölçeği (Bouncken vd., 2014; Chen vd., 2015; Hughes ve Morgan, 2007) değerlendirme aracı olarak kullanılmıştır ve hipotezler Smart-PLS 2.0 ile test edilmiştir. Araştırma bulgularına göre, üstbilişsel, motivasyonel ve davranışsal kültürel zekanın girişimcilik yöneliminin risk alma, yenilikçilik ve proaktiflik boyutlarından bazıları ile arasında anlamlı bir ilişki olduğu ortaya konmuştur.
\end{abstract}

Anahtar Kelimeler:Kültürel Zeka, Girişimcilik Yönelimi, Mikro Ölçekli Iş̧letmeler, Türkiye JEL Sinıflandirmasi: M10, L26

\section{The Effect Of Cultural Intelligence On Entrepreneurship Orientation: A Field Study Of Micro Enterprises In Istanbul Laleli Market}

\begin{abstract}
In a highly competitive environment businesses interact stakeholders who come from different cultures. The interaction of individuals from different cultures can cause communication problems. In terms of overcoming communication problems caused by cultural differences, cultural intelligence is a developing field of study for management scientists. The purpose of this study is to determine the effect of cultural intelligence on entrepreneurship orientation. In order to test the main hypotheses data were collected from micro scale enterprises in Laleli market by questionnaire method. Cultural intelligence scale (Ang, Van Dyne, Koh, Ng, Templer, Tay ve Chandrasekar 2007) and entreprenurial orientation scale (Bouncken vd., 2014; Chen vd., 2015; Hughes ve Morgan, 2007) were used as assesment tools of the questionaire. Hypotheses tested with Smart-PLS 2.0 programme. Tests results show that metacognitive, motivational and behavioral cultural intelligence has a significant effect on some of the dimensions of entrepreneurial orientation such as risk taking, innovation and proactivity.
\end{abstract}

Key Words: Cultural Intelligence, Entrepreneursip Orientation, Micro Enterprises, Turkey JEL Classification: M10, L26

\footnotetext{
* İstanbul Üniversitesi Sosyal Bilimler Enstitüsü, İşletme Bölümü. ugk_koyuncu@ @otmail.com ORCID Bilgisi: 0000-0003-4512-4333

** Dr. Öğr. Üyyesi. İstanbul Üniversitesi, İktisat Fakültesi, İsletme Bölümü. bakdol@istanbul.edu.tr ORCID Bilgisi: 0000-0002-7613-9856
} 


\section{GİRIŞ}

Günümüzün zorlu rekabet şartları altında girişimcilerin ve işletmelerin faaliyetlerine devam edebilmeleri ancak uluslararası pazarlara açılmaları ile mümkün olmaktadır. Ancak bu pazarlarda farklı kültürden kişilerin olması bazı zorluklara neden olabilmektedir. Bu zorlukların aşılmasında kullanılan araçlardan bir tanesi olan kültürel zeka ile işletmelerin hem kültürlerarası alandaki başarısı hem de girişimcilik yönelimlerinin artması beklenebilmektedir. Çünkü kültürel zeka ile kişiler kültürlerarası ilişkilerde daha başarılı olmakta ve bunu girişimlerinde bir avantaj olarak kullanmaktadırlar. Bu öngörü ile kültürel zekanın girişimcilik yönelimine olan etkisini araştırmak bu çalışmanın öncelikli amacıdır.

\section{KÜLTÜREL ZEKA}

Earley ve Ang (2003)'e göre kültürel zeka kişilerin farklı kültürel ortamlara uyum sağlayabilme yeteneğidir. Kültürel zeka bir insanın çeşitli kültürel ortamlarda farklı insanlarla olan ilişkilerinin ve etkileşimlerinin kalitesini belirlemektedir (Triandis, 2006: 20). Bir başka tanıma göre, ırk, etnik köken ve milliyet farklılıklarından kaynaklı kültürel farklılıkların etkileşimini hedefleyen bir yapı olarak kültürel zeka bir kişinin farklı kültürel geçmişe sahip insanlarla etkin bir şekilde anlaşma kabiliyet ve kapasitesidir (Nafei, 2013: 27). Kültürel zeka, bir beceri olarak, bir insanın farklı kültürlerden insanların çalışma ortamındaki jest ve mimiklerini, olaylara bakış açılarını ve düşünce yapılarını sanki o kültürden biriymiş gibi zihninde anlayarak yorumlaması, nihayetinde yeni bakış açısına uygun davranışlar sergilemesini sağlayan yetiler dizisidir (Early ve Mosakowski, 2004: 139).

İlk kez Earley ve Ang (2003) tarafindan üç boyutlu olarak ortaya atılan kültürel zeka, daha sonra Ang, Van Dyne, Koh, Ng, Templer, Tay ve Chandrasekar (2007) tarafından geliştirerek dört boyutlu olarak ölçeklendirilmiştir. Yeni modelde zihinsellik (bilişsel) boyutu ikiye ayrılarak, bilişsel kültürel zeka ve üstbilişsel kültürel zeka olarak tanımlanmıştır.

Üstbilişsel kültürel zeka, kültürel bilginin edinilmesinde ve anlaşılmasında kullanılan zihinsel süreçleri yansıtmaktadır (Ang vd., 2007: 338341). Üstbiliş, kendi bilişsel süreçlerimizin bilgisidir (Barbato vd., 2014: 526). Bir bakıma kişinin neyi ne kadar bildiğinin ve nasıl öğrendiğinin farkında olmasıdır (Aksoy, 2015: 97). Üstbilişsel kültürel zeka kişilerin strateji oluşturma kabiliyetidir. Buna göre üstbilişsel kültürel zeka farkındalık (kültürlerarası ortamlarda kültürel farklılıkları anlamlandırma), planlama (bilgi eksikliği durumunda bu eksikliği gidermeye yönelik strateji geliştirme) ve kontrol etme (kişinin kendi etkileşimlerini gözden geçirmesi) süreçlerinden oluşmaktadır. (Early ve Peterson, 2004: 109-110; Van Dyne, Liwermore ve Ang, 2010: 137).

Bilişsel kültürel zeka, herhangi bir kültürle ilgili genel bilgiyi ve bilgi yapılarını simgelemektedir (Earley ve Ang, 2003). Bilişsel kültürel zeka yeni kültürel bilgileri yakalama, işleme ve analiz etme yeteneğidir (Helms vd., 2014). Kişiler, diğer kültürlerin iktisadi, hukuki, eğitimsel ve sosyal düzenlerine dair sahip oldukları genel kültürel bilgiyi bilişsel kültürel zekaları aracılığıyla 
edinmektedirler. Bu bilginin edinilmesi genellikle sistematik eğitim veya deneyim yoluyla gerçekleşmektedir. (Şahin ve Gürbüz, 2012: 127).

Motivasyonel kültürel zeka, kütürlerarası ortamlarda ilgili kültürü öğrenme ve öğrenilen bilgileri uygulama yönündeki kişilerin enerji yönü ve yoğunluğunu ifade etmektedir (Ang, Van Dyne ve Koh, 2006: 101). Bu yönüyle motivasyonel kültürel zeka, kültürel farklılıkların olduğu ortamlarda belirli bir görev veya herhangi bir durum için bir çalışanın enerji ve dikkatini yönlendiren ve sürdüren zihinsel kapasitesi olarak tanımlanmaktadır (Ang vd., 2007: 337339). Motivasyonel kültürel zeka içsel motivasyon (farklı kültürel ortamlardan keyif alma), dışsal motivasyon (farklı kültürel deneyimlerden sağlanan somut kazanımlar) ve öz fayda (kültürlerarası karşılaşmalarda etkili olmak) olmak üzere üç alt boyuttan oluşmaktadır (Livermore, 2010: 26).

Davranışsal kültürel zeka, kişilerin farklı kültürlerle etkileşim kurarken uygun sözlü ve sözsüz davranışları sergileme yeteneğini ifade etmektedir (Ang, Van Dyne ve Koh, 2006: 101). Davranışsal kültürel zekası gelişmiş olan çalışanlar farklı kültürel ortamlarda uygun ses tonu, konuşma hızı, jest ve mimikler sergileme konusunda başarılı olmaktadırlar ( $\mathrm{Ng}$, Van Dyne ve Ang, 2009: 515). Davranışsal kültürel zeka, bir çalışanın bilişsel ve motivasyonel potansiyelini davranışları aracılığıyla yansıtabilmesiyle yakından ilgilidir (Aksoy, 2015: 107).

Farkl11ıkları yönetmede önemli bir strateji olarak görülen kültürel zeka (Yeşil, 2009: 101), farklı kültürel özelliklere sahip çalışanları tanıma, anlama ve uygun davranışlar gösterebilme (uygun yönetim anlayışı gösterebilme) avantajı sağlamaktadır. Böylelikle kültürel farklılıktan kaynaklanan çatışmalar etkili bir şekilde yönetilebilmektedir. (Early ve Ang, 2003: 9). Bununla birlikte kültürel zeka, kişilerin farklı bakış açıları geliştirmelerini sağlayarak (Yeşil, 2009: 116), karşılaşılan farklı kültürel problemleri doğru bir şekilde nedenselleştirerek onlara dair spesifik yorumlar yapmasına ve potansiyel sorunlara alternatif çözümler geliştirmesine yardımcı olmaktadır (Ang v.d., 2007: 337). Böylelikle işletmeler muhtemel problem ve kriz durumlarında kültürel zekaları sayesinde birbirleriyle fikir alış verişi yaparak sağlıklı sonuçlara ulaşabilmektedirler. Bu faydalar ise işletmelere rekabet avantajı sağlamakta (Yeşil, 2010: 164) ve işletme karlılığ artmaktadır. (Aslan ve Aslan, 2015: 41).

\section{KÜLTÜREL ZEKANIN GİRIŞIMCILİK YÖNELIMİNE ETKİSi}

Girişimcilik yönelimi, stratejik bir seçim ve yönelim olarak bir girişimde bulunma yönünde bireyin arzu ve isteğine bağlı eylemler olarak ortaya çıkan ve planlanmış davranışlara dönüşen bir süreç olarak ifade edilmektedir (Timuroğlu ve Çakır, 2014: 121). Bireysel ve çevresel faktörlerin bir birleşimi olarak görülen girişimcilik yönelimi, bireylerin kendi işlerini kurma konusundaki istek, kararlılık ve kendilerine olan güvenleriyle ilgili görülmektedir (Güreşci, 2014: 24; Salik ve Kaygın, 2016: 147). Girişimcilik yönelimi işletmelerde yönetim kademelerinde uygulanmakta olup risk alma, yenilikçilik ve proaktiflik yönelimini arttırmak amacıyla uygulanan stratejik bir işletme davranışı şeklinde nitelendirilebilmektedir (Yeşil, Doğan ve Doğan, 2016: 154). Bu çalışmada da 
girişimcilik yönelimi üç boyut (risk alma, yenilikçilik, proaktiflik) olarak kabul edilmektedir.

Risk alma, bireyin sonuçları ne olacağı konusunda kesin bir bilgiye sahip olmadan, makul bir başarısızlık düzeyini göze alarak yeni girişimlere yönelimini ifade etmektedir (Fiş ve Wasti, 2009: 132). Risk alma bilinmeyen iş alanlarına yapılan cesur hamleler ve/veya belirsizlik koşulları altında girişimde bulunulacak işe önemli kaynakların tahsis edilmesidir (Engelen, Kube, Schmidt ve Flatten, 2014: 1354).

Yenilikçilik, bir kişinin yönetimsel ve operasyonel açılardan girişimlerde bulunurken yeni ürün, hizmet veya yöntem ile sonuçlanan bir süreci harekete geçirmek için yeni fikirler deneme yöneliminde olmasıdır (Engelen, Kube, Schmidt ve Flatten, 2014: 1354). Yenilikçiliğin, işletmelerin yeni ürünler, hizmetler, yöntemler, teknolojiler vs. üretmesi ya da geliştirmesi dışında önemli bir diğer amacı karşılaşılan sorunlara yaratıcı ve farklı çözümler getirmesidir. Ayrıca radikal olma derecelerine göre farklılıklar gösterse de yenilikler temelde var olan teknoloji ve uygulamaları terk etme isteğine dayanmaktadır. (Beğendik, 2013: 110).

Proaktiflik, fırsat arayışının yüksek seviyede olması, ileride gerçekleşen müşteri taleplerinin önceden tahmin edilmesi ve rakiplerinin önünde olmakla karakterize edilmektedir (Engelen, Kube, Schmidt ve Flatten, 2014: 1354). Proaktiflik, bir kişinin yönetimsel ve operasyonel açılardan uygulamaya soktuklarının ilk kez kendisi tarafindan yapılıyor olmasıyla ilgilidir (Fiş ve Wasti, 2009: 132). Proaktiflik işletmenin yeni gelişmeleri olabildiğince erken tahmin etmeye istekli olması ve yeni gelişmeleri beklemek yerine, rakipler karşısında "ilk hamle" olarak hareket eden işletme olma arzusuyla işletmenin stratejik duruşunun yönünü yansitmaktadır (Frank, Kessler ve Fink, 2010: 180).

Girişimciler, yeni girişim yaratmada ülkeler için merkezi bir role sahip olmaktadırlar (Baron, 2007: 167). Ancak yeni bir girişimde bulunmak işletmelere karmaşık bir ortamda faaliyet gösterme zorluğunu beraberinde getirmektedir. $\mathrm{Bu}$ zorlukların üstesinden gelmek için girişimcilerin, girişimci kişilik özelliklerini (risk alma, yenilikçi olma, proaktiflik) benimsemeleri gerekmektedir. (Muzychenko, 2008). Bu noktada kültürel zeka becerisi kişilerin girimci olma yönlerini beseleyen bir yeti olabilir.

\section{A. Araștırma Hipotezlerinin Olușturulması}

Üstbilişsel kültürel zeka ile çalışanlar farklı kültürden bireylerle etkileşim esnasında, söz konusu kültürü ne kadar bildiklerini ve bilmediklerini farketmektedirler. Bu farkındalığın girişimcilik yönelimi üzerinde pozitif yönde etkili olabileceği ileri sürülebilir. Jun (2012), kültürel mirasın korunması ve yenilikçiliğin kapsamlı bir şekilde geliştirilebilmesi için üniversite öğrencilerinin üstbilişsel zekasının geliştirilmesi gerekliliği üzerinde durmuştur. Yeni bilgilerin öğrenilmesi ve uygulamaya konması arasındaki boşluğa dikkat çeken BlodgettMcDeavitt ve Dirkx (1995), yeniliklerin benimsenmesinin ve mevcut bakış açılarının değiştirilmesinin ancak üstbilişsel zeka aracılığıyla mümkün olabileceğini belirtmektedirler. Yabancı bir kültürü ne kadar tanıyı 
tanımadığımız üzerinde farkındalık geliştirmemize imkan sağlayan üstbilişsel zeka, farklı kültürlerle işbirliği yapmamızı gerektiren yeni girişimlerde, girişimciye avantaj sağlayabilir. Tüm bu varsayımlardan hareketle, bu çalışmada test edilmek üzere aşağıdaki hipotez geliştirilmiştir.

H1: Üstbilişsel kültürel zeka, girişimcilik yönelimini etkilemektedir.

Kültürel açıdan bilişsel zekalarını geliştirmiş kişiler farklı kültürlerin sosyal yaşamları hakkında genel bir bilgiye hakim olmaktadırlar (Ang, vd., 2007). Berglund (2005), bilişsel zeka ile kişilerin bilgilerini geliştirdiklerini böylece özgüven duygusunun arttığını söylemişlerdir. Buna bağlı olarak girişimcilerin risk algısı azalarak yeni bir girişimde bulunma yönelimleri artırmaktadır. Bilişsellik ve risk alma arasındaki ilişkinin kişinin girişimcilik yönelimindeki rolünü araştıran Barbosa, Gerhardt ve Kickul (2007), yüksek risk tercihi olan kişilerin genel itibariyle firsatları belirleme özelliğine sahip kişiler olduğunu, düşük risk tercihinde bulunan kişilerin ise, daha fazla ilişki kurma eğilimli ve toleranslı olduklarını ortaya koymuşlardır. Ayrıca bilişsel beceriler yenilik yapmada itici güç olarak da görülmektedir (Messinis ve Ahmed, 2013). Swan (1997), bir çalışmasında teknolojik yeniliklerle ilgili kararlarda bilişsel zekanın önemini vurgulamıştır. Bilişsel kültürel zekanın sayesinde, çalışanları farklı kültürlerle etkileşim gerektiren girişimleri başlatma konusunda cesaretlendiği iddia edilebilir ve bu varsayımdan hareketle bu çalışmadan test edilmek üzere aşağıdaki hipotez geliştirilmiştir.

H2: Bilişsel kültürel zeka, girişimcilik yönelimini etkilemektedir.

Motivasyonel kültürel zeka çalışanların farklı kültürden kişilerle olmaktan keyif almalarını sağlamakta ve onları yeni kültürel ortamlara ilişkin faaliyetlerde bulunmaları için girişimci olmaya itmektedir (Aksoy, 2015: 104). Hamilton (1974), yüksek başarı motivasyonuna sahip kişilerin, orta düzeydeki riskleri alma yöneliminde olduklarını ve başarısızlığı önleme yönünde yüksek motivasyona sahip olanların ise bu risklerden kaçınmaya eğilimli kişiler oldukları tespitinde bulunmuştur. Dewett (2007), içsel motivasyonun bazı öncüllerle kişilerin risk alma yönelimine aracılık ettiğini kanıtlamıştır. Dulaimi, Ling ve Bajracharya (2003), işletmelerin gelecekle ilgili iyimser olmaları onların motivasyonlarını arttırarak yenilikleri benimsemelerini etkilediğini söylemişlerdir. Joo ve Lim (2009), motivasyonun ve proaktiflik kişilik özelliğinin birbirini etkilediğini ortaya koymuşlardır.

H3: Motivasyonel kültürel zeka, girişimcilik yönelimini etkilemektedir.

Yüksek kültürel zekaya sahip bir çalışan bilişsel stratejileri sayesinde kültürlerarası etkileşime enerjisini ve dikkatini kolaylıkla yönlendirebilmekte ve davranışsal kültürel zeka aracılığıyla da uygun sözlü ve sözlü olmayan davranışları sergilemede esnek davranabilmektedir (Ang ve Van Dyne, 2008; Earley ve Ang, 2003; Livermore, 2010; Ng vd., 2011). Bu yetkinliğin ise kişilerin girişimcilik yönelimlerini olumlu yönde etkilemesi beklenmektedir. Hurley ve Hult (1998) yüksek yenilikçiliği, öğrenme, gelişme ve katılımcı karar vermeyi vurgulayan kültürlerle bağdaştırmışlardır. Buna göre davranışsal kültürel zeka sayesinde diğer kültürlerle samimi ilişkiler kuran çalışanlar, muhatabı olduğu 
kültürlerle ilgili bilgileri öğrenebilmekte, kendini geliştirebilmekte ve dolayısıyla yenilikler konusunda daha aktif olabilmektedirler. Bu varsayımdan hareketle bu çalışmada test edilmek üzere aşağıdaki hipotez geliştirilmiştir.

H4:Davranışsal kültürel zeka, girişimcilik yönelimini etkilemektedir.

\section{LALELİ PAZARINDA MIKRO ÖLÇEKLI İŞLETMELERDE KÜLTÜREL ZEKANIN GIRIŞIMCILIK YÖNELIMMINE ETKİSI ÜZERINE BİR ARAŞTIRMA}

\section{A. Araştırma Yöntemi}

1991'de Sovyetler Birliği'nin dağılmasıyla Rusya ve Türkiye arasında işbirliği artmış ve Laleli Semti bir dönem bavul ticareti merkezi haline gelmiştir (Hepaktan, Y1lmaz ve Özden, 2009:1- 2018:12). Fakat günümüzde bavul ticareti yerini kayıtlı mikro ihracata bırakmıştır. Bu anlamda Laleli sayıları 7 bine ulaşan kayıtlı işletmesi ile Türkiye'nin mikro ihracat anlamında önemli merkezlerinden biri haline gelmiştir. (https://www.star.com.tr/ekonomi/laleliye-mujde-haber1438488/, 2019). Bununla birlikte Avrupa ve Asya arasında bir köprü görevi gören, Ortadoğu, Balkanlar ve Avrupa'nın kesiştiği bir turizm merkezi olan Laleli Pazarı (Akyüz,t.y.:16) özellikle Türk tekstil sektörünün önde gelen işletmelerinin yer aldığı, otelleri ve seyahat acenteleri ile altyapısı oturmuş bir hizmet ağına sahiptir (Türkmen, 2013:77). Laleli pazarındaki farklı ölçekteki pek çok işletmedeki çalışanlar, her gün farklı kültürden müşteriler ve iş ortaklarıyla iletişim kurmaktadırlar. Özellikle mikro ölçekli işletmelerde sahip-çalışanların yabancılarla geliştirdiği kaliteli bir etkileşimin, işletme başarısı ve devamlılığı üzerindeki etkisinin önemli olduğu düşünülebilir. Bu araştırmanın amacı, Laleli pazarındaki mikro ölçekli işletmelerde çalışanların kültürel zekaları ile girişimcilik yönelimleri arasındaki ilişkiyi ve kültürel zekanın alt boyutlarının girişimcilik yönelimine etkisini ortaya koymaktır. Araştırmanın amacına uygun olarak araştırmanın modeli Şekil 1.’de gösterildiği gibi oluşturulmuştur.

Şekil 1. Araştırma Modeli

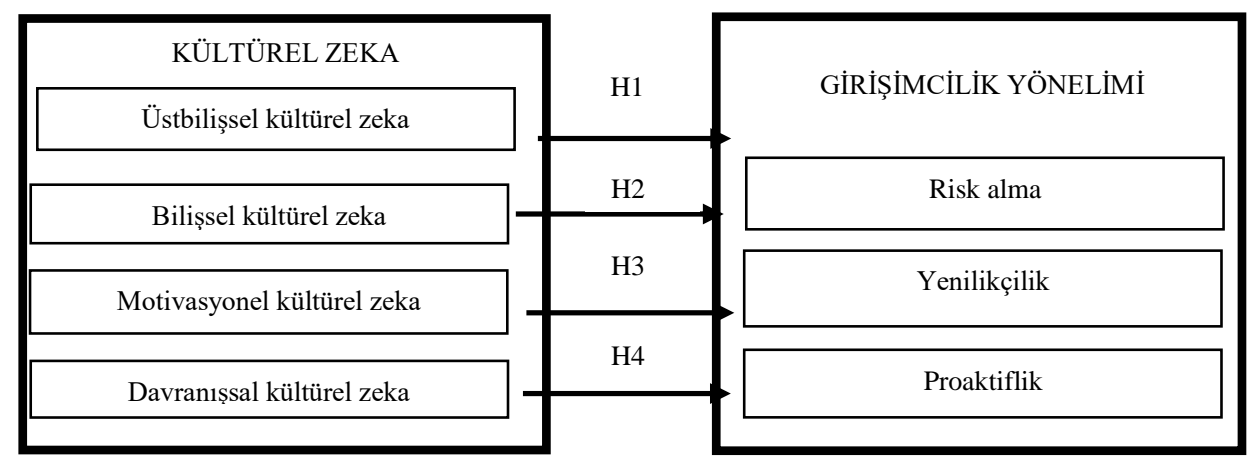

Araştırma modelini oluşturan değişkenleri ölçmek için Bouncken, Plüschke, Pesch ve Kraus (2014), Chen, Chang, ve Chang (2015) ve Hughes ve Morgan (2007) tarafından geliştirilen 21 sorudan oluşan girişimcilik yönelimi ölçek soruları ve Ang, S., Van Dyne, L., Koh, C., Ng, K.Y., Templer, K.J., Tay, C. ve Chandrasekar, A. (2007) tarafından geliştirilen 20 soruluk kültürel zeka 
değerlendirme araçları kullanılmıştır. Söz konusu iki değerlendirme araçlarına iliş̧in ifadeler 5'li Likert tipi ölçek ile değerlendirilmiştir. Girişimcilik yönelimi ve kültürel zekaya ilişkin ifadelerin yanı sıra demografik sorular da eklenerek anket formu oluşturulmuştur. Anket formu yüz yüze görüşme yönetimi ile Laleli pazarında faal olan çalışanlara uygulanmıştır. 161 kişiyle görüşmeler yapılarak veri toplanmıştır. Çalışmada Laleli pazarının seçilmesinin nedeni, pazarın farklı kültürden çalışan ve müşterilere ev sahipliği yapmasıdır.

\section{B. Örneklemin Demografik Özellikleri}

$\mathrm{Bu}$ çalışmada örneklemin büyük çoğunluğu $(\% 95,7)$ erkektir. Katılımcıların \%20'si 35 yaş altı, \%63'ü 35-55 yaş arasında \%17'si 55 yaş üstüdür. Eğitim seviyeleri incelendiğinde, \%31'in ilköğretim, \%42'nin lise, \%4'ün meslek yüksek okulu, \%14'ün üniversite, \%2'nin lisans üstü eğitime sahip olduğu görülmüştür, \%8 eğitim düzeyini belirtmekten kaçınmıştır. Tüm bu demografik özellikler göz önünde bulundurularak, örneklemin çoğunlukla orta yaşl1, yüksek öğrenim görmemiş erkeklerden oluştuğunu söylemek mümkündür.

Katılımcıların işletmedeki rolleriyle ilgili veriler ise şu şekildedir: \%52'si çalışan ve \%44'ü işletme sahibidir. Katılımcıların \%4'ü bu bilgiyi paylaşmak istememiştir. Katılımcıların \%13'ü 5 yıldan az, \%46's1 6-15 y1l arası, \%44'ü 16 yıldan daha fazla aynı pazarda tecrübeye sahiptir. Katılımcıların faal oldukları sektörlere ait istatistiki veriler ise şu şekildedir: \%6'sı dayanıklı tüketim malları, $\% 71$ 'i tekstil, $\% 2$ 'si dernek, $\% 9$ 'u lojistik ve $\% 5$ 'i hazır gıda sektöründedir. Katılımcıların \%7'si sektörleriyle ilgili bilgiyi paylaşmamıştır.

\section{Araştırma Analizleri ve Bulguları}

Çalışmada oluşturulan modelin test edilmesi amaciyla Smart-PLS 2.0 programı kullanılmıştır (Ringle, Wende ve Will, 2005). Bu programın tercih edilme sebebi gözlem sayısının görece düşük olduğu araştırmalarda daha iyi sonuçlar vermesidir. Laleli pazarındaki mikro ölçekli işletmelerde az sayıda çalışan, hatta bazen işletme sahibinin (girişimcinin) tüm faaliyetleri yürüttüğü bir yapı söz konusudur. Bu nedenle pazardaki pek çok işletme çalışanı ile görüşülmüş olsa da gözlem sayısı çok artamamaktadır. Bu durumda SPSS gibi sıklıkla kullanılan paket programları dışında, küçük örneklemlerde daha etkili sonuçlar veren Smart-PLS programının tercih edilmesi uygun bulunmuştur.

Analizlere başlamadan önce ölçeklerin geçerlilik ve güvenirlikleri test edilmiştir. Bu esnada SPSS 20.0 Programı keşfedici faktör analizi ve güvenilirlik testi için kullanılmıştır. Daha sonra ise, yukarıda belirtildiği gibi Smart-PLS programı ile hipotezler test edilerek bulgulara ulaşılmıştır. Bu çalışma, kültürel zekanın girişimcilik yönelimine etkisini inceleyen yeni bir model sunduğundan ve örneklem boyutu da görece küçük olduğundan $(\mathrm{N}=161)$, kısmi en küçük kareler yol analizi hipotez testi için en uygun yaklaşım olarak görülmüştür.

\section{1. Ölçüm Geçerliliği ve Güvenirliliği}

Kültürel zeka ve Girişimcilik yönelimi ölçeği, Türkçe bir çalışmada ilk kez kullanılacağından öncelikle kültürel zeka değişkenin keşfedici faktör analizine tabii tutulması uygun görülmüştür. Bu çerçevede SPSS 20.0 programı kullanılmak suretiyle, varimaks döndürmeli temel bileşenler faktör analizi 
seçilerek soru öğelerinin bir faktör altında mı yoksa çoklu olarak mı dağıldıkları kontrol edilmiştir. Beklenildiği üzere, kesme değeri 1 olan özdeğerli (eigenvalue) dört anlamlı faktör ortaya çıkmıştır. Tüm ifadelerin faktör yüklerinin ,60'dan büyük oldukları sonucuna ulaşılmıştır. (Hair, Anderson, Tatham ve Black, 2010). Sonrasında, toplanan verilerin faktör analizine uygunluğunu görmek amaciyla, Kaiser-Meyer-Olkin (KMO) katsayısına (Kaiser, 1970; Dziuban ve Shirkey, 1974) ve Bartlett küresellik testi (the Bartlett test of sphericity) (Bartlett, 1950) skoruna bakılmıştır. Kültürel zeka için KMO değerinin ,78, girişimcilik yönelimi için ,79 olması (,70’den büyük olmalıdır) ve Bartlett küresellik testi neticesinin anlamlı olması çalışmanın veri setinin keşfedici faktör analiz için uygunluğunu göstermiştir. Son olarak, değişkenlerin ortalama varyans, birleşik güvenirlik ve Cronbach alfa katsayısı değerleri kontrol edilmiştir. Değerlerin, Nunnally (1978) ve Fornell ve Larcker (1981) tarafından belirlenen eşik seviyelerinin üzerinde oldukları görülmüştür. (Bknz, Tablo.1) Ortaya çıkan bu istatistiki veriler ile ölçeklerin tek boyutlu oldukları ve yeterli geçerlilik ile güvenirlik değerlerine sahip oldukları sonucuna ulaşılmıştır.

Tablo 1. Korelasyonlar ve Tanımlayıcı İstatistikler

\begin{tabular}{clccccccc}
\hline No & Değişkenler & 1 & 2 & 3 & 4 & 5 & 6 & 7 \\
\hline 1 & Üstbilişşel Kültürel Zeka & - & & & & & & \\
2 & Bilişssel Kültürel Zeka &, $29^{* *}$ & - & & & & & \\
3 & Güdüsel Kültürel Zeka &, $38^{* *}$ &, $38^{* *}$ & - & & & & \\
4 & Davranışsal Kültürel Zeka &, $47^{* *}$ &, $32^{* *}$ &, $39^{* *}$ & - & & & \\
5 & Risk Alma &, $33^{* *}$ &, $26^{* *}$ &, $21^{* *}$ &, $42^{* *}$ & - & & \\
6 & Yenilikçilik &, $39^{* *}$ &, $29^{* *}$ &, $38^{* *}$ &, $41^{* *}$ &, $30^{* *}$ & - & \\
7 & Proaktiflik &, $30^{* *}$ &, $27^{* *}$ &, $53^{* *}$ &, $22^{* *}$ &, $35^{* *}$ &, $46^{* *}$ & - \\
\hline & Ortalama & 3,83 & 3,22 & 3,76 & 3,55 & 3,66 & 4,03 & 3,74 \\
& Standart Sapma &, 81 &, 88 &, 82 &, 82 &, 91 &, 74 &, 73 \\
\hline & Çkarılan Ortak Varyans &, 59 &, 55 &, 61 &, 65 &, 60 &, 62 &, 56 \\
& Birleşik Güvenirlik &, 85 &, 86 &, 86 &, 88 &, 81 &, 87 &, 83 \\
& Cronbach Alfa &, 78 &, 80 &, 79 &, 82 &, 71 &, 79 &, 73 \\
\hline
\end{tabular}

$* p<, 05 ; * * p<, 01$.

Araştırma modelinin test edilmesi için kısmi en küçük kareler regresyonuyapısal eşitlik modeli (PLS-YEM) kullanılmıştır. PLS-YEM'in, önemli bir özelliği birçok bağımlı değişken ile bağımsız değişkeni aynı model dâhilinde analiz edebilmesidir (Chin, 1998). Teorik model kapsamındaki var oldukları iddia edilen ilişkilerin istatistiksel yönden anlamlılıklarını test etmek amacıyla SmartPLS 2.0 programında önyükleyerek yeniden-örnekleme metodu (bootstrapping resampling method) (Chin, 1998) kullanılmıştır. Tablo 3'de hipotez testi sonuçları gösterilmektedir. 
Tablo 2 . Hipotez testi sonuçları

\begin{tabular}{|c|c|c|c|c|c|c|}
\hline & & Yol & & Beta Değeri & Hipotez & Sonuç \\
\hline $\begin{array}{l}\text { Üstbilişsel } \\
\text { Zeka }\end{array}$ & Kültürel & $\rightarrow$ & Risk Alma &, $18^{* *}$ & H1a & Desteklendi \\
\hline $\begin{array}{l}\text { Üstbilişsel } \\
\text { Zeka }\end{array}$ & Kültürel & $\rightarrow$ & Yenilikçilik &, $19^{* *}$ & $\mathrm{H} 1 \mathrm{~b}$ & Desteklendi \\
\hline $\begin{array}{l}\text { Üstbilişsel } \\
\text { Zeka }\end{array}$ & Kültürel & $\rightarrow$ & Proaktiflik &, $14 * *$ & $\mathrm{H} 1 \mathrm{c}$ & Desteklendi \\
\hline $\begin{array}{l}\text { Bilişssel } \\
\text { Zeka }\end{array}$ & Kültürel & $\rightarrow$ & Risk Alma &, 11 & $\mathrm{H} 2 \mathrm{a}$ & Desteklenmedi \\
\hline $\begin{array}{l}\text { Bilişsel } \\
\text { Zeka }\end{array}$ & Kültürel & $\rightarrow$ & Yenilikçilik &, 10 & $\mathrm{H} 2 \mathrm{~b}$ & Desteklenmedi \\
\hline $\begin{array}{l}\text { Bilişssel } \\
\text { Zeka }\end{array}$ & Kültürel & $\rightarrow$ & Proaktiflik &, 07 & $\mathrm{H} 2 \mathrm{c}$ & Desteklenmedi \\
\hline $\begin{array}{l}\text { Motivasyonel } \\
\text { Kültürel Zeka }\end{array}$ & & $\rightarrow$ & Risk Alma &,- 03 & $\mathrm{H} 3 \mathrm{a}$ & Desteklenmedi \\
\hline $\begin{array}{l}\text { Motivasyone } \\
\text { Kültürel Zeka }\end{array}$ & & $\rightarrow$ & Yenilikçilik &, $18^{* *}$ & $\mathrm{H} 3 \mathrm{~b}$ & Desteklendi \\
\hline $\begin{array}{l}\text { Motivasyone } \\
\text { Kültürel Zeka }\end{array}$ & & $\rightarrow$ & Proaktiflik &, $48^{* *}$ & $\mathrm{H} 3 \mathrm{c}$ & Desteklendi \\
\hline $\begin{array}{l}\text { Davranışsal } \\
\text { Zeka }\end{array}$ & Kültürel & $\rightarrow$ & Risk Alma &, $32 * *$ & $\mathrm{H} 4 \mathrm{a}$ & Desteklendi \\
\hline $\begin{array}{l}\text { Davranışsal } \\
\text { Zeka }\end{array}$ & Kültürel & $\rightarrow$ & Yenilikçilik &, $22 * *$ & $\mathrm{H} 4 \mathrm{~b}$ & Desteklendi \\
\hline $\begin{array}{l}\text { Davranışsal } \\
\text { Zeka }\end{array}$ & Kültürel & $\rightarrow$ & Proaktiflik &,- 05 & $\mathrm{H} 4 \mathrm{c}$ & Desteklenmedi \\
\hline
\end{tabular}

Analiz sonuçlarına göre, kültürel zekanın ilk boyutu olan üstbilişsel kültürel zekanın girişimcilik yöneliminin boyutlarıyla arasındaki hipotez testi sonuçları şu şekildedir: üstbilişsel kültürel zeka, risk almayı $(\beta=, 18 ; p<, 01)$, etkilemektedir $(\beta=, 19 ; p<, 01)$, proaktifliği $(\beta=, 14 ; p<, 01)$ etkilemektedir. $\mathrm{Bu}$ sonuçlara göre, $\mathrm{H} 1$ tamamen desteklenmiştir.

Kültürel zekanın ikinci boyutu olan bilişsel kültürel zekanın girişimcilik yöneliminin boyutlarıyla arasındaki hipotez testi sonuçları şu şekildedir: bilişsel kültürel zeka, risk almayı $(\beta=, 11 ; p>, 01)$, yenilikçiliği $(\beta=, 10 ; p>, 01)$, ve proaktifliği $(\beta=, 07 ; p>, 01)$ etkilememektedir. Bu sonuçlara göre, $\mathrm{H} 2$, tamamen reddedilmiştir.

Kültürel zekanın üçüncü boyutu olan motivasyonel kültürel zekanın girişimcilik yöneliminin boyutlarıyla arasındaki hipotez testi sonuçları ise şu şekildedir: motivasyonel kültürel zeka, risk almayı etkilememektedir $(\beta=-, 03 ; p$ 
$>, 01)$; motivasyonel kültürel zeka, yenilikçiliği $(\beta=, 18 ; p<, 01)$ ve proaktifliği $(\beta=, 48 ; p<, 01)$ etkilemektedir. Bu sonuçlara göre, $\mathrm{H} 3$ ana hipotezinin bazı alt hipotezleri kabul, bazıları ise reddedilmiştir.

Kültürel zekanın dördüncü boyutu olan davranışsal kültürel zekanın girişimcilik yöneliminin boyutlarıyla arasındaki hipotez testi sonuçları ise şu şekildedir: davranışsal kültürel zeka, risk almayı $(\beta=, 32 ; p<, 01)$ ve yenilikçiliği $(\beta=, 22 ; p<, 01)$ etkilemekte, proaktifliği $(\beta=-, 05 ; p>, 01)$ etkilememektedir. Bu sonuçlara göre, $\mathrm{H} 4$ kısmen kabul edilmiştir.

\section{SONUÇ}

Birlikte yaşamanın getirdiği zorlukların başında kültürel farklılıkları anlamlandırabilmek gelmektedir. Operasyonel verimlilikten ziyade insanlar sayesinde işletme performansının yükseldiği 21. yy. iş dünyasında, kültürel farklılıkların yönetilmesinde kullanılan önemli stratejilerden biri de kültürel zekadır. Özellikle kültürel zeka, farklı kültürlerden tarafların iletişiminin yoğun olduğu iş ortamlarında, çalışanların kültürel farklılıklara gereken önemi vermesi ve uyum sağlaması neticesinde işletmesinin uzun vadeli rekabet üstünlüğüne ve varlığını sürdürebilme amacına ulaşmasını sağlamada önemli bir yetenek olarak görülmektedir. Bir başka deyişle girişimci, yönetici ve çalışanların kültürel zeka düzeyi yüksek olmasının, yeni girişimler, süreç ve yöntemler ortaya koyma eğilimini de arttırdığ 1 söylenebilir. Bu çalışmada İstanbul Laleli pazarındaki mikro ölçekli işletmeler üzerine yapılan hipotez testi sonuçlarına göre; kültürel zekanın, bilişsel zeka alt boyutu dışındaki tüm boyutlarının girişimcilik yöneliminin çeşitli boyutları üzerinde etkisi olduğu ortaya konmuştur. Böylece Türkiye'de farklı kültürlerden bireylerin bir arada iş yaptığı ortamlarda ortamlarda, bir başka deyişle çalışanların turistlerle etkileşimde bulunduğu mikro ölçekli işletmelerde kültürel zekanın yüksek olması, çalışanların risk alma, yenilik yapma ve proaktif davranma eğilimlerine pozitif bir etkisi olduğu ortaya konmuştur.

Bu çalışma kapsamında yapılan hipotez testi sonuçlarına göre üstbilişsel kültürel zeka girişimcilik yöneliminin tüm boyutları üzerinde pozitif bir etkiye; motivasyonel kültürel zeka yenilikçilik ve proaktiflik boyutları üzerinde pozitif bir etkiye; davranışsal kültürel zeka ise risk alma ve yenilikçilik boyutları üzerinde pozitif bir etkiye sahiptir. Öte yandan bilişsel kültürel zeka ve girişimcilik yönelimi arasında anlamlı bir ilişki bulunmamaktadır. Hipotezlerin bazılarının desteklenmemesinin nedenleri arasında; örneklemin eğitim seviyelerinin düşük olması sebebiyle bilgi ve özgüven yetersizliğinin olması, Türk toplumunun girişimcilikle ilgili geleneksel kültürel yapısı sebebiyle bireylerin başarısızlık korkusu yaşamaları gibi faktörler ileri sürülebilir.

$\mathrm{Bu}$ çalışmanın sonucuna göre, kişiler girişimcilik yönelimi kapsamında kendilerini ve çalışanlarını kültürel zeka açısından geliştirmek için motive etmelidirler. Çünkü araştırma sonuçları da göstermiştir ki, kültürel zeka çalışanları diğer kültürler bakımından birçok yetkinliğe kavuşturarak onları farklı kültürlerle etkileşim gerektiren girişimcilik faaliyetleri açısından desteklemektedir. Günümüz toplumlarında kişilerin istek ve beklentilerindeki 
değişim yakalanamaz bir hıza ulaşmıştır. Böyle bir toplumda özellikle uluslararası pazar özelliği gösteren Laleli pazarı çalışanlarının değişime ayak uydurması ancak muhatabı olduğu kültürleri tanımaları ve onları anlamalarıyla gerçekleşecektir.

Bu çalışma sadece Türk kültüründe, belirli bir bölgede, belirli ölçek ve sektördeki işletmelerin var olduğu bir pazarda gerçekleştirilmiştir. Öte yandan örneklemin demografik özellikleri benzer pazarların özelliklerini de yansitabilecek şekilde homojen dağılmamaktadır. Bu nedenle sonuçlar sadece İstanbul Laleli pazarındaki mikro ölçekli işletmeleri temsil etmektedir ve bulguların genellenmesi mümkün değildir. $\mathrm{Bu}$ araştırma sonuçları farklı anakütlelerle yapılacak ileriki çalışmalarla da desteklenmelidir.

\section{KAYNAKÇA}

Aksoy, Z. (2015). Kültürel Zeka: Kültürlerarası İletişim ve Yönetimde Çağdaş Bir Yaklaşım, Istanbul: Beta Yayıncılık.

Akyüz, İ., “'Laleli Bavul Turizmi Cenneti', Kişisel Arşivlerde İstanbul Belleği, Taha Toros Arşivi.

Ang, S., Van, D. L., Koh, C., NG, K. Y., Templer, K.. J., Tay, C. and Chandrasekar, A. (2007)

"Cultural Intelligence: Its Measurement and Effects on Cultural Judgment and Decision Making, Cultural Adaptation and Task Performance', Management and Organization Review, Vol 3, No 3, 335-371.

Ang, S., Van, D. L. and Koh, C. (2006). "Personality correlates of the four-factor model of cultural intelligence", Group and Organization Management, Vol 31, No 1, 100-123.

Ang, S. and Van, D. L. (2008). "Conceptualization of Cultural Intelligence: Definition, Distinctiveness, and Nomological Network", Handbook on Cultural Intelligence: Theory, Measurement and Applications, 3-15.

Aslan, S. ve Aslan, Ö. (2015). “İstanbul'daki 5 Yıldızlı Otellerde Kültürel Zeka Ölçeğine İlişkin Bir Uygulama', İstanbul Üniversitesi Iktisat Fakültesi Ekonometri ve İstatistik Dergisi, Say1 23, 34-61.

Barbosa, S. D., Gerhardt, M. W. and Kickul, J. R. (2007). "The Role of Cognitive Style And Risk Preference On Entrepreneurial Self-Efficacy And Entrepreneurial Intentions", Journal of Leadership \& Organizational Studies, Vol 13, No 4, 86-104.

Barbato, M., Penn, D. L., Perkıns, D. O., Woods, S. W., Liu, L. and Addington, J. (2014). "Metacognitive Functioning in Individuals at Clinical High Risk For Psychosis", Behavioural and cognitive psychotherapy, Vol 42, No 5, 526-534.

Baron, R. A. (2007). "Behavioral and Cognitive Factors in Entrepreneurship: Entrepreneurs as The Active Element in New Venture Creation", Strategic Entrepreneurship Journal, Vol 1, No $1-2,167-182$

Beğendik, B. (2013). "Küresel Doğan İşletmelerin Uluslararasılaşma Sürecine Etki Eden Girişimcilik Yönelimi Boyutları ve Girişimci Özellikleri’", Gazi Üniversitesi Sosyal Bilimler Enstitüsü İsletme Anabilim Dalı Doktora Tezi.

Berglund, H. (2005). "Toward a Theory of Entrepreneurial Action-Exploring Risk”, In Chalmers University of Technology.

Blodgett-Mcdeavitt, C. and Dirkx, J. M. (1995). "Metacognition, Metamemory, and Commitment to Change Strategy: Enhancing Adoption of Innovation of Staff Development', Midwest Research-to-Practice Conference in Adult, Continuing, and Community Education, National Louis University, Wheaton, IL, Online Submission, 1-16.

Bouncken, R. B., Plüschke, B. D., Pesch, R. and Kraus, S. (2014). "Entrepreneurial orientation in vertical alliances: joint product innovation and learning from allies", Orginal Paper.

Chen, M. H., Chang, Y. Y. and Chang, Y. C. (2015). "Entrepreneurial Orientation, Social Networks, and Creative Performance: Middle Managers as Corporate Entrepreneurs", Creativity and Innovation Management, Vol 24, No 3, 493-507. 
Chin, W. W. (1998). "The Partial Least Squares Approach for Structural Equation Modeling', In George A. Marcoulides (Eds.), Modern Business Research Methods Mahwah, NJ: Lawrence Erlbaum Associates, Vol 295, No 2, 295-336.

Dewett, T. (2007). "Linking Intrinsic Motivation, Risk Taking, And Employee Creativity In An R\&D Environment', $R \& D$ Management, Vol 37, No 3, 197-208.

Dulaimı, M. F., Ling, F. Y. And Bajracharya, A. (2003). "Organizational Motivation And InterOrganizational Interaction In Construction Innovation In Singapore", Construction Management and Economics, Vol 21, No 3, 307-318.

Early, P. C. and Ang, S. (2003). Cultural Intelligence: Individual Interactions Across Cultures, California: Stanford University Pres.

Early, P. C. and Mosakowski, E. (2004). "Cultural Intelligence”, Harvard Business Review, Cilt 82, Say1 10, 139-146.

Early, P. C. and Peterson, R. S (2004). "The Elusive Chameleon: Cultural Intelligence as a New Approach to Intercultural Training for the Global Manager", Academy of Management Learning and Education, Vol 3, No 1, 100-115.

Engelen, A., Kube, H., Schmidt, S. and Flatten, T. C. (2014). "Entrepreneurial Orientation in Turbulent Environments: The Moderating Role of Absorptive Capacity", Research Policy, Vol 43, 1353-1369.

Fiş, A. M. ve Wasti, S. A. (2009). “Örgüt Kültürü ve Girişimcilik Yönelimi İlişkisi’”, ODTÜ Gelişme Dergisi, 35(Özel Sayı), 127-164.

Frank, H., Kessler, A. and Fink, M. (2010). "Entrepreneurial Orientation And Business Performance-A Replication Study", Schmalenbach Business Review, Vol 62, 175-198.

Fornel, C. and Larcker, D. F. (1981). "Evaluating Structural Equation Models With Unobservable Variables and Measurement Error", Journal of Marketing Research, Vol 18, Say1 1, 39-50.

Güreşçi, E. (2014) “Girişimcilik Eğilimi Üzerine Bir Araştırma: İspir Hamza Polat MYO Örneği', Girisimcilik ve Kalkinma Dergisi, Cilt 9, Say1 1, 23-38.

Hamilton, J. O. (1974). "Motivation and risk taking behavior: A test of Atkinson's theory", Journal of Personality and Social Psychology, Vol 29, No 6, 856.

Helms, M. M., Rutt1, R. M., Lorenz, M., Ramsey, J. and Armstrong, C. E. (2014). “A Quest For Global Entrepreneurs: The Importance of Cultural Intelligence on Commitment to Entrepreneurial Education', International Journal of Entrepreneurship And Small Business, Vol 23, Say1 3, 385-404.

Hepaktan, C. E., Yılmaz, M. ve Özden, B. (2009:1- 2018:12). “Türkiye' de Bavul TicaretiEkonomik Büyüme İlişkisi’’.

Hughes, M. and Morgan, R. E. (2007). "Deconstructing the relationship between entrepreneurial orientation and business performance at the embryonic stage of firm growth", Industrial Marketing Management, Vol 36, Say1 5, 651-661.

Hurley, R. F. and Hult, G. T. M. (1998). "Innovation, Market Orientation, And Organizational Learning: An Integration And Empirical Examination', The Journal of Marketing, Vol 62, No 3, 42-54.

Ishafan1, A. N., Jooneghan1, R. B. N. and Azar, M. (2013). "Analyzing the Effects of Cultural Intelligence on Employee Performance in Azaran Industrial Group (Isfahan Province)", International Journal of Academic Research in Business and Social Sciences, Vol 3, Say1 5, 363-376.

Joo, B. K. and Lim, T. (2009). “The Effects of Organizational Learning Culture, Perceived Job Complexity, And Proactive Personality on Organizational Commitment And Intrinsic Motivation', Journal of Leadership And Organizational Studies, Vol 16, No 1, 48-60.

Jun, D. I. N. G. (2012). " From Ontological Knowledge, Personalized Intelligence to the Mapping of Meta-cognitive Value — On the Mental Principles \& Operative Routes for Universities to Practice Cultural Inheritance and Innovation [J]", Journal of Nanjing University of Science and Technology (Social Sciences Edition), 2, 002.

Livermore, D. (2010). "Leading With Cultural Intelligence: The New Secret to Success", New York, Amacom. 
Messinis, G. and Ahmed, A. D. (2013). "Cognitive Skills, Innovation And Technology Diffusion', Economic Modelling, Vol 30, 565-578.

Muzychenko, O. (2008). "Cross-cultural Entrepreneurial Competence in Identifying International Business Opportunities", European Management Journal, Vol 26, No 6, 366-377.

Nafei, W. A. (2013). "The Impact of Cultural Intelligence on Employee Job Performance: An Empirical Study on King Abdel-Aziz Hospital in Al-Taif Governorate, Kingdom of Saudi Arabia”, International Journal of Business and Management, Vol 8, 26-43.

Ng, K. Y., Van, D. L. and Ang, S. (2009). "From Experience to Experiential Learning: Cultural Intelligence as a Learning Capability for Global Leader Development', Academy of Management Learning \& Education, Vol 8, Sayı 4, 511-526.

Nunnaly, J. C. (1978). "Psychometric theory (2nd edit.) McGraw-Hill”, Hillsdale, NJ.

Ringle, C. M., Wende, S. and Will, A. (2005). "SmartPLS - Version 2.0.', Universität Hamburg.

Salik, N. ve Kaygın, E. (2016). "Demografik Değişkenler Açısından Üniversite Öğrencilerinin Girişimcilik Eğilimlerinin Belirlenmesi: Kafkas Üniversitesi Örneği”, Kahramanmaraş Sütçü İmam Üniversitesi Sosyal Bilimler Dergisi, Cilt 13, Sayı 1, 145-162.

Swan, J. (1997). "Using Cognitive Mapping in Management Research: Decisions About Technical Innovation”, British Journal of Management, Vol 8, Say1 2, 183-198.

Şahin, F. ve Gürbüz, S. (2012). "Kültürel Zekâ ve Öz-Yeterliliğin Görev Performansı ve Örgütsel Vatandaşlık Davranışı Üzerinde Etkisi: Çok Uluslu Örgüt Üzerinde Bir Uygulama", "İ̧s, Güç”' Endüstri İlişkileri ve Insan Kaynakları Dergisi, Cilt 14, Sayı 2, 123-140.

Timuroğlu, M. K. ve Çakır, S. (2014). "Girişimcilerin Yeni Bir Girişim Yapma Niyetlerinin Risk Alma Eğilimi İle İlişkisi”, Afyon Kocatepe Üniversitesi İkitsaid ve İdari Bilimler Fakültesi Dergisi, Cilt 16, Say1 2, 119-136.

Triandis, H. C. (2006). "Cultural Intelligence in Organisations", Group and Organisations Management, Vol 31, No 1, 20-26.

Türkmen, E. (2013). "Otel İşletmelerinde Değere Dayalı Pazarlama Uygulamalarının Belirlenmesi: Laleli Örneği”, Ballkesir Üniversitesi Sosyal Bilimler Enstitüsü Turizm İşletmeciliği ve Otelcilik Anabilim Dalı Yüksek Lisans Tezi.

Van D. L., Ang, S. and Livermore, D. (2010). "Cultural Intelligence: A Pathway For Leading in a Rapidly Globalizing World", Leading across differences, 131-138.

Yeşil, S. (2009), “Kültürel Farklılıkların Yönetimi ve Alternatif Bir Strateji: Kültürel Zeka”, KMU IIBF Dergisi, Cilt 11, Sayı 16, 100-129.

Yeşil, S. (2010). “21. Yüzyılın Küresel Örgütleri İçin Kültürel Zekâ', Ç. Ü. Sosyal Bilimler Enstitüsü Dergisi, Cilt 19, Say1 2, 147-168.

Yeşil, S., Doğan, İ. F. ve Doğan, Ö. (2016). “Örgüt Kültürünün Girişimcilik Yönelimi İle Örgütsel Performans Üzerindeki Etkisi: Kahramanmaraş İli Tekstil Sektörü Örneği', Yönetim ve Ekonomi Araştırmaları Dergisi. Cilt 14, Sayı 1, 150-172.

https://www.star.com.tr/ekonomi/laleliye-mujde-haber-1438488/ (2019, 8 Mart). Laleli'ye Müjde. Star.com.tr

\section{SUMMARY}

We live in a world in which interactions of people from different cultures increase every day. It is important to be aware of the cultural differences and their impact. Particularly, this is much more important for the companies operating across the cultural boundaries. Researches indicate that companies engaging in across the countries face several dilemmas, one of which is cultural differences. The success of companies doing business worldwide depends on understanding and managing cultural difference. In terms of overcoming communication problems caused by cultural differences, cultural intelligence is a developing field of study for management scientists. Cultural intelligence as the ability to adapt the verbal and nonverbal behaviors to the new culture, enable employee to maintain 
an effective communication with the other culture's members. Cultural intelligence has four dimensions; metacognitive cultural intelligence (storing information of different cultures in mind, recall when needed, plan for learning if there is a lack of information), cognitive cultural intelligence (general knowledge about different cultures), motivational cultural intelligence (desire to behave in accordance with different cultures), behavioral cultural intelligence (behave in accordance with the knowledge). A higher degree of cultural intelligence is also important for the managers and entrepreneurs and managers who develops their skills and capacity for cultural intelligence tens to be willing to take risk, act proactively and innovate more than their competitors. Entrepreneurship orientation has three dimensions. Risk (investing in situations where the results are unknown), innovation (finding original solutions for needs), proactive (being a pioneer in implementing innovations). Entrepreneurship orientation is a process that will lead a person to exhibit entrepreneurial behavior. orientation is the precursor of behavior. Today, culturel intelligence is a tool in overcoming challenges. Cultural intelligence is expected to increase the entrepreneurial orientation of individuals.

The purpose of this article is to determine the relationship between cultural intelligence and entrepreneurial orientation. A survey method was used to collect data form the employees of the micro business in Laleli Market in Turkey. Cultural intelligence scale (Ang, Van Dyne, Koh, Ng, Templer, Tay ve Chandrasekar 2007) and entreprenurial orientation scale (Bouncken vd., 2014; Chen vd., 2015; Hughes ve Morgan, 2007) were used as assesment tools of the questionaire. Hypotheses tested with Smart-PLS 2.0 programme. Tests results show that metacognitive, motivational and behavioral cultural intelligence has a significant effect on some of the dimensions of entrepreneurial orientation such as risk taking, innovation and proactivity. 